\title{
The Cyber Space-Time Continuum: Meaning and Metaphor
}

\section{Adrian Mihalache}

Politechnica University of Bucharest, Bucharest, Romania
Various spatial metaphors related to cyberspace suffer from two major deficiencies. First, they do not take into account that cyberspace is not a preexistent territory, but an entity that emerges in the process of its development. Second, cyberspace is not a metric space, so that most of the ready-made constructs, like the topologic spaces, cannot be of much use. An interpretation of Blake's works helps one to understand that cyberspace is not a purely spatial entity; it also involves time, but not in the sense of Einstein's special relativity theory. The cyber space-time continuum is not a void waiting to be filled, but an aggregation of places (sites) that, similarly to Blake's plates, are multimedia architectures resulting from the blend of space and time.

Keywords Blake, cyberspace, multimedia, vortex, World 3

The Web has mainly been perceived as a kind of space. We attempt a critical examination of the various spatial metaphors related to cyberspace and point out two major deficiencies. First, they do not take into account that cyberspace is not a preexistent territory to be conquered, civilized, colonized, and so on, but an entity that emerges in the process of institution development. Second, cyberspace is not a metric space, so that most of the ready-made constructs, like the topologic spaces or the relativistic timespace continuum, cannot be of much use.

An interpretation of William Blake's works, especially of the anti-Newton excerpts from the Prophetic Books, proves extremely useful for the understanding of cyberspace. This is not a purely spatial entity; it also involve s time, but not in the sense of a supplementary variable that would account for the concept of simultaneity, like in Einstein's special relativity theory. The cyber space-time

Received 11 May 2000; accepted 9 November 2001.

Address correspondence to Adrian Mihalache, Politechnica University of Bucharest, Sos lancului 27, BI. 105D, sc. A, ap. 58, Bucharest, Romania. E-mail: mad@dnt.ro continuum is an aggregation of places (sites), not a space waiting to be filled. A place (site) is similar to a plate from Blake's works: They both are multimedia architectures. Moreover, the site is also a blend of space and time. The spatial component is given by the "pages" one explores successively, according to various paths. Additionally, there are two duration s involve d in the time experience of a site in cyberspace. One belongs to the cybersmith, the creator of the site. It is the compression and the transfiguration of the author's history, the spatial objectivation of the limitless time of an in-depth experience. The other is the variable time of exploration, which is controlle $d$ by the cybernaut. The fusion between the two brings forth the magic moment of encounter.

Any activity in cyberspace may be described by the time transaction involved whenever a cybernaut explores a site. In cyberspace, "time is money" does not mean an equivalence, but a substitution. Cyber-economic models would describe more accurately the exchange processes of the virtual economy if they realized that the exchange of time plays in cyberspace the same part as the monetary exchange in real life.

\section{CYBERCULTURE AND ITS ADEPTS}

The high-tech expert, as well as the barely computerliterate person, who spends long hours in front of his or her monitor, still belongs to real-life culture, as long as the system he or she converses with is self-contained, duly stuffed with all the application s software usually required. Whether one uses an autonomous computer for data or text processing, for problem solving, daily planning, improving one's abilities, or just for fun, one remains solidly rooted in the values, beliefs, and meanings of the world as we know it. Obviously, it is a dramatically changing world, wherein technological improvements may have important social consequences, wherein the relationship of multiple effects to multiple causes cannot be traced on a one-toone basis, and wherein small increments can trigger disproportionate responses. However, it is still our world; we 
can still describe it according to the traditional framework of system sciences, we can still trace its continuity along its various leaps and bounds, and we may still nurture the hope of preserving its essential values and precious achievements.

As soon as computers got interconnected via the various networks that form the Internet, an alternative culture was born. The e-mail, bulletin boards, discussion groups, and chat rooms created new types of human interaction, while web surfing, web editing, and web promotion set forth new cultural constructs. The network provided new means of communication, and moreover, the possibility of easy access to the data and knowledge bases resident on servers. This easy access suggests an alternate open society, which promotes unrestricted intercourse, in the name of the principle that "information wants to be free." Against this principle stands the fact that the geography of the Web is not entirely seamless. It is partitioned into open areas and intranets, proprietary networks, and sites, the latter involving a subscription or a membership code. We believe, however, that the open domains are more prone to stimulate the development of new ideas and practices, based on the free exchange of suggestion s and critiques. It is precisely in these areas that the people-on-the-Net, as a result of their specific practices and unrestricted debates, develop their own values, beliefs, and meanings - in short their own culture. A satisfactory provisional definition of this cyberculture is posted by David Silver on his excellent site Resource Center for Cyberculture Studies (Resource Centre for Cyberculture Studies, 2001): Cyberculture is a collection of cultures and cultural products that exist on and/or are made possible by the Internet, along with the stories told about these cultures and cultural products. Cyberculture, as well as the cybersociety that supports and develops it, has its own location, the mysterious realm of cyberspace. We believe that a proper description of cyberculture should start with an in-depth analysis of cyberspace.

\section{METAPHORS OF CYBERSPACE}

\section{The Electronic Frontier}

The word "cyberspace" was coined by an inspired cyberpunk writer (Gibson, 1984). The success of the term stems from the fact that it supported, and at the same time added a high-tech flavor to, the basic intuition that the interconnection of computers brings forth a sort of new "space," wherein one could travel seemingly without effort from one place to another. The discourse developed within the influential cybercommunity "The Well" also made use of spatial metaphors, such as the "Electronic New Frontier," which suggested a newly found world to be studied, chartered, civilized, even, horribile dictu, colonized. The mission statement of the Electronic Frontier Foundation (EFF), an organization that emerged from the mentioned cyber-community, openly states that the EFF has been established "to help civilize the electronic frontier" (our emphasis). The somewhat "imperialist" overtones of this metaphor did not escape the attention of the guardians of political correctness. Protests were heard (Sardar \& Ravetz, 1996) against a neo-colonialis $m$ that would spread on the net the values and symbols of the wealthy Western elites (Kolko, Nakamura, \& Rodman, 2000). However, the metaphor of the new frontier exhibits worse flaws than the complacency toward the culture of the establishment. It presupposes the existence of cyberspace, prior to any civilization attempt, as a territory to be explored, conquered, and fashioned. Thus, one easily overlooks the fact that regions of cyberspace come into being one by one, in the process of founding and developing cyber-institutions .

\section{The Empyrean Realm}

Another spatial metaphor for cyberspace, more indebted to the Western cultural tradition than to Western imperialism, is Christian Heaven. Wertheim (1999) argues that cyberspace is precisely the technological implementation of the Empyrean Realm. Here are the reasons why: It is open for everyone (that is, for those who can afford it), it is not reserved to a certain nation or race, it is populated with disembodied entities (very similar to angels), and it has no internal frontiers or communication barriers, thus providing excellent remedies against loneliness. Moreover, since each intellectual profile can be preserved in a continuously maintained database, it also offers the promise of immortality. Wertheim's discourse culminates with the computopian (computer utopian) revelation of the "immaterial realm" (p. 229), of the blissfully "shared space" (p. 233), where one gets the sense of "the rich and believable world" (p. 234). An emotional overtone rings out: "in cyberspace we transcend the limitation s of the body, we remain young, ubiquitou s etc., etc." The main foible of such an analysis is that it takes cyberspace as a pretext to give once again a learned account of the story of the European construction, deconstruction, invention, and reinvention of the concept of space. It takes for granted that the network of computers brings forth another space to be included in the sequence of "spaces" that have been imagined along the history of European thought. The perspective space, understood as an illusionist technology announcing virtual reality, stands side by side with the Newtonian space. The various hyperspaces, non-Euclidean, Hilbertian, or purely abstract, together with the relativistic space-time continuum are rather arbitrarily treated as harbingers of cyberspace. However, the specific properties of these "spaces" are far from being relevant for cyberspace. ${ }^{1}$ Again, the same point is missed as in the case of the "electronic frontier" metaphor: 
The prefix "cyber" should be understood as a process of space creation, not as a technological, salutary intervention into a previously existing space. Moreover, the cyberspace is formed by the interconnection of various data and knowledge bases; thus, it is more an intellectual space than a spiritual one. The fallacy of the cultural discourse, which reverts to the history of space in order to explain cyberspace, is similar to the one Polonius is committing in Hamlet, II, 1, when he starts to explain Hamlet's madness by restating the definitions of space, folly, and time.

\section{Possible Worlds and Mathematical Spaces}

A more systematic and in-depth contribution to the ontology of cyberspace is provided by Coyne (1995). He also starts from the intuitive observation that "the Internet technology makes space within its own virtual environment" (p. 151) and attempts to support it with arguments, some of them reasonable, a few rather commonplace, and others quite misleading. The cyberspace has, according to him, a threefold meaning: It is a "world," a "space," and a "place." First, cyberspace qualifies as a world because the collection of physical entities (hardware, wiring, software) that forms the cyberspace infrastructure is a subset of the physical world (cf. p. 153). Apart from being obvious, this statement brings forth a reductive metonymy, in the sense that it derives a property of cyberspace from the characteristics of its material ingredients. Figures such as metonymy do not hold open the possibility of transference, only the possibility of substitution (cf. Peterfreund, 1998, p. 127). That is, metonymy makes possible a form of reification, suggesting that cyberspace is little more than the result of the functioning of these palpable informational engines that are part of a world, our world. Second, Coyne claims that cyberspace is a "world" in the same sense as "the world of art" or "the world of finance"- that is, it is the support of various communities and of their practices (cf. p. 153). However, these communities are not worlds in the sense of spatial extension; they are, according to any accepted definition, cultures. A culture needs an ambience to develop itself in, and cyberspace provides such an environment for cyberculture. However, the advent of cyberculture cannot account for the qualification of its medium as a "space." Coyne provides a more fruitful insight by reverting, although inexplicitly, to the mathematical definition of space, as a set of objects and rules of interaction, such that any operation performed according to the aforementioned rules keeps the result within the same space (cf. p. 155). The main operations in cyberspace are (a) navigation (from one web site to another), (b) web-site design and implementation, and (c) message transmission. All these operations do not transgress the virtual limits of cyberspace; they do not point to the real world. Thus, this mathematical outlook would be appealing, were it not focused on topological and abstract spaces, which are meant to express, as precisely as possible, the notion of "nearness." Euclidean space, Hilbert space, and other various hyperspaces are described in terms of the "norm," which is a generalization of the notion of distance. Most such spaces are metric spaces, wherein the relevant issue is that two objects (points) are either near to, or far from, each other. Coyne thinks that such issues are quite relevant in cyberspace too: "Similarly [to the abstract, mathematical space], objects that occupy cyberspace can be near to, or far from, each other, adjacent, and so on, and one can specify where we are in terms of an address.... In 3D space [or any mathematical space], we can measure distances. In cyberspace, we can measure path lengths in terms of the number of nodes traversed" (cf. p. 155). Contrary to Coyne, we believe that in cyberspace the notion of distance is irrelevant. Thinking about cyberspace as a topological graph, its nodes (vertices) symbolize the sites located on the servers and its edges represent the links that may be activated. The length of a path from one node to another is by no means a limitation as far as the duration of the transmission is concerned. The main technical limitation on the net is the bandwidth (the channel capacity measured in bytes per second), not the length of the route to be followed. Consequently, in cyberspace, the address does not specify a physical location, such as the distance from a hypothetic center; it signifies a symbolic position, and the closer to the top level, the stronger it is (Introna $\&$ Nissenbaum, 1999). Another argument Coyne brings in favor of the perception of the cyber-medium as a space is the fact that cyberspace is apt to reproduce or represent Cartesian space. "If physical space can be represented with three-dimensional coordinates, then this information can be stored, manipulated, transformed etc." (p. 156). While it is obvious that a database can contain the spatial coordinates of material points, thus describing the relative positions of objects in space, we do not think that this endows the database with spatial features. The representation of space is not necessarily a space, in the same sense that the portrait of a woman is not a woman.

\section{FROM SPACE TO PLACE}

The metaphors in use, associated with cyberspace, suffer from two major deficiencies. First, they do not account for the fact that cyberspace is not a metric space; moreover, it is not a purely spatial entity, but it also involves time, albeit not in the sense of Einstein's special relativity theory. Second, they ignore that cyberspace is not a preexistent territory, but a spatio-temporal entity that emerges in the process of its development. We deal with the first objection in the present section and with the second in the next.

An important intuition concerning cyberspace is that it enables and constrains human interaction in ways similar 
to physical space; that is, the behavior patterns it favors are intimately connected with space (p. 156). We have seen that web design, web navigation, and web communication are operations that keep us within cyberspace, while strongly suggesting kinesthetic sensations. Moreover, these sensations are aggregated in experiences that involve time, as well as space. This statement can be interpreted at a primary, obviou s level. The direct communication in a chat room is an experience that involves real time and a sensation of proximity. Reading e-mail or exploring a web site gives one an informational experience that incorporates the time involved in the composition of the letter or in the construction of the web site. However, there is also a less commonplace outlook on the blending of space and time in cyberspace. Most pages (viewed, as we shall see as "places") are the spatial incorporation of duration; they are stuff made of time compressed. One would be tempted to look at the relativistic space-time continuum in order to find a clue for including time in cyberspace. But the relativistic space is itself a metric space, wherein the time is just another pseudo-spatial coordinate, needed to account for the finite speed of all signals. Consequently, the phenomenology of cyber space-time cannot make much of the relativistic discourse. It can, however, take advantage of the qualitative notion of "place."

\section{The Temporality of Web Sites}

Any site on the Web has a temporal dimension, which can best be understood with reference to the virtual space of fine arts. André Malraux (1965) was aware of the time dimension of the perspectival space of the painting. He commented on Leonardo's works as follows: "Leonardo created, systematized or imposed, several years before Hieronymus Bosch, a space Europe had never suspected before, a space which was not merely the receptacle of bodies, but one that swept both painted figures and viewers into infiniteness, in a similar way that Time works" (p. 14). This kind of time intrusion is, however, related mainly to the representation of movement. The art history offers a better example, the engraved works of William Blake.

The fact that William Blake was one of the first multimedia artists is highly meaningful. He was not just an illustrator of his works, a painter that doubled the poet. $U t$ pictura poesis (poetry works similarly to painting) could not have been his motto, for he did not suggest analogies between the narrative and the figurative, nor did he try to express the same meaning by two rival, independent discourses - linguistic and visual. He blended the text and the image into one engraved plate, and treated paradoxically the latter as a message and the first as an icon. He actually engraved the text itself, which implied the drudgery of drawing it on copper as if seen in a mirror, only in or- der to integrate better the two media into an intricate and unitary combination. According to Kaplan (2000), "Blake created a procedure that enabled him to operate on a unified surface, making all the marks-letters or leaf-stem, word or world-with the same tool and to the same effect" (p. 35). Blake's method allowed him the artistic freedom to mix typographic and iconographic elements, words and images, within the same space on the printed page. Thus, he qualified as a harbinger of multimedia technology. The plates, which compose Blake's works, should not be either "read" sequentially, or contemplated as independent pictures. They have to be explored by successive choices, along various paths, following a procedure not very different from the one a cybernaut uses when visiting a site on the Web. The pages of a site may be unfolded in multiple sequences; the links from one multimedia component to another can be activated at will. The depth of a site is more related to time than to space. The web surfer, while exploring its superposed pages, is absorbed in a stream of conscious ness that makes him or her experience directly the "lived duration." The temporality of cyberspace emerges, according to Rieusset-Lemarié (2000/2001), from "the plastic interplay of colours and texture related to the various paths in the hypertextual site." The temporal dimension of site exploration gives the inordinate chance to convey time as an experience. "The progression is itself the experience. The stake of this æsthetics of progression is not founded first and foremost on the perception of shapes, but on the dimension of experience as progression" (Rieusset-Lemarie, 2000/2001)

Many cyber-artists share an organic conception of their work, which they claim related to action painting (RieussetLemarié, 2000/2001). For them, the Web is a new "canvas" where new, unpredictable shapes emerge from the dynamic structure of hyperlinks. Action painting is related to time via the body movements of the artist. In cyberspace, the techniques of "artificial life," based on chaos theory, are sometimes employed in order to trigger creative processes. The web artist Joseph Ventrella says: "As an artist, I am interested in writing computer programs that would generate dynamic systems which would develop in time, like living entities" (quoted in Rieusset-Lemarié, 2000/2001). Similarly, the use of algorithms that generate visual structures changing in real time simulates the process of surface alteration. Here, the temporality that informatics involves is based on the execution time required by a program.

The minute precision of Blake's craftsmanship is related to the approach of today's web artists, but the philosophy behind it offers a deeper insight into both their procedures. Blake's technology is based on his belief that "Art \& Science cannot exist but in minutely organized Particulars/And not in generalizing Demonstrations of the Rational Power" (William Blake, Jerusalem, plates 55, 62-63). Kaplan (2000) emphasizes the fact that "The real 
value of printing in the infernal method is neither its efficiency nor its novelty, but rather its æsthetic or metaphysical power" (p. 28). He set as an ambitious goal for multimedia technology to reach "an apocalypse of perception, an end to false division s between space and time, between body and soul" (p. 25). His work suggests that there are two durations involved in the time experience of a plate or, conversely, of a site in cyberspace. One belongs to the cybersmith, the creator of the site. It is the compression and the transfiguration of the author's history, the spatial objectivation of the limitless time of an in-depth experience. The other is the variable time of exploration, which is controlled by the cybernaut. The fusion between the two brings forth the magic moment of encounter. The exploration of a site offers the possibility to connect the real time of the visitor's live experience with the compressed, spatially encapsulated time of the web-site development. Blake (Milton, plates 15, 21-27) uses a striking metaphor for expressing this encounter, the vortex.

\footnotetext{
The nature of infinity is this: That every thing has its Own Vortex; and when once a traveller thro Eternity. Has passd that Vortex, he percieves it roll backward behind His path, into a globe itself infolding; like a sun:

Or like a moon, or like a universe of starry majesty, ...

Or like a human form, a friend with whom he livd benevolent.
}

The art of multimedia humanizes the cyberspace by populating it with "vortexes" that provide opportunitie s for meaningful, sometimes admirable, encounters. The occurrences of such encounters are the magic events in the cyber space-time continuum.

\section{The Place as Spatial-Temporal Synthesis}

The metaphor of the "vortex" implies that a web site is not merely a point in space, but a spatial-temporal synthesis, which we call a "place." Place is a space with experience added in (Sewall, 1999, p. 167). A place, such as one of Blake's plates or a web site, compresses in a spatial unit the time required for the imagination of the designer to be converted and, consequently, objectified, into a cybercultural construct. The encounter between subjectivity and a place (between the cyber surfer and a web site) may trigger an event, that is, "a sequence of moments, with meaning added to the mix of moments" (Sewall, 1999, p. 168). The event is deepened into an experience by the interaction of the various media employed in a site's construction. According to Sewall (1999), the "depth" of an experience is the dimension, which arises from the gathering together of images, sounds, scents, etc. (cf. Sewall, 1999, p. 169). Consequently, the multimedia involved in Blake's works or in web design is essential in transforming the encounter events into lived, meaningful experiences. The repeated experiences and the complex associations they involve include the place (site) in our memories and affections. Place experiences are necessarily time deepened and memory qualified (Ralph, 1985, pp. 15-31). Cyberspace is not the result of connecting points in a metric space, but the constellation of places, which are activated by genuine cyber-experiences.

\section{"CREATING SPACE, CREATING TIME": BLAKE'S VISION OF CYBERSPACE}

Blake's works provided a fruitful insight in the blending of space and time into the notion of "place" as an element of cyberspace. We do not intend here to transform Blake into a harbinger of cyberspace; rather, we claim that his work provides metaphors that prove meaningful for a deep understanding of cyberspace. Moreover, his Prophetic Books offer a cue for the emergence of cyberspace through a creative act.

\section{Newton's Sleep}

William Blake warned his contemporaries against the dangers of the "single vision," of the reductive worldview, originated in "Newton's sleep." While the sleep of Reason yielded monsters, ${ }^{2}$ Newton's sleep brought forth his natural philosophy. This would eventually become, for almost three centuries, the unanimously accepted physical theory of the movement of bodies, from corpuscles to planets, and it would provide the mechanistic framework for understanding and explaining practically any issue in terms of forces and accelerations. However, the triumphant march of the rational mechanics would not proceed unchallenged. Soon, Newton's sleep would awaken Blake's inspiration, and he would reclaim the primacy of the Poetic principle over the rational one: "If it were not for the Poetic or Prophetic character, the Philosophic \& Experimental would soon be at the ratio of all things \& stand still, unable to do other than repeat the same dull round over again" (William Blake, There is No Natural Religion, $b$ ).

Blake is a singular voice against Newton's account of the world, at least among his English contemporaries. According to Peterfreund (1998), the intellectuals of the time, such as Addison, Pope, Desaguliers, and Johnson, "may have disagreed over the extent to which Newtonian physics could, by argument from analogy, be used to help see the subjective aspects of the universe in an orderly manner. But these and other writers of the eighteenth century were of one mind concerning the objective truth of Newtonian physics per se" (p. 21). It was only in the question of how far Newtonian thought might be extended into other spheres of inquiry than physics and mathematics, that there was any real debate. It is true that, as an opponent of Newton, Blake is in the distinguishe d company of such Europeans as Leibniz and Goethe. However, 
the critiques of the latter are restricted to specific matters. Leibniz is concerned with his priority as far as calculus is concerned, Goethe with the promotion of his own optical theory. Blake's attitude (from William Blake's Notebook) is not only radical, but also derisive:

\footnotetext{
You dont [sic] believe I wont [sic] attempt to make ye

You are asleep I wont [sic] attempt to wake ye

Sleep on Sleep on while in your pleasant dreams

Of Reason you may drink of Lifes clear streams

Reason and Newton they are quite two things

For so the Swallow \& the Sparrow sings

Reason says Miracle. Newton says Doubt

Aye thats [sic] the way to make all Nature out
}

Blake goes straight to the point and addresses the very core of Newton's approach, the concepts of absolute space and time. He is little inclined to accept the idea of a preexistent "void," wherein the corpuscles dance blindly, under the command of reciprocally exerted forces. This would be nothing else than "a void immense, wild, dark \& deep/Where nothing was: nature's wide womb" (William Blake, The Book of Urizen, plate 4, II, 16-17). He claims "voids and absolute space exist only for those who do not fill them with plenitude" (Peterfreund, 1998, p. 31). Moreover, Blake warns that failure of filling up the void results in the void filling us, thus undermining the unity of our interiority and fragmenting our perception and understanding onto the fallen categories of Newtonian time and space (cf. p. 31). His fundamental intuition is that space, as well as time, are not absolute, preexistent categories, but are generated by the human poetical drive (Blake, Jerusalem, plate 98, 24-32):

\footnotetext{
The Four Living Creatures...

... conversed together in Visionary forms dramatic which bright

Redounded from their Tongues in thunderous majesty, in Visions

In new Expanses, creating exemplars of Memory and of Intellect

Creating Space, Creating Time according to the wonders Divine

Of Human Imagination.
}

It is clear from this that space is created together with time in the act of founding "places" in cyberspace. These places, as we have seen are spatial-temporal synthesis, which concentrate past experiences and generate new ones.

Peterfreund believes that "the Newton's critiques in the Prophetic Books and especially in Milton are anticipatory, in the essentials, of the insights set forth by relativity physics concerning the space-time continuum and other matters in the latter physics' correction of the Newtonian model" (p. 22). Our opinion is that Blake's intuition moves rapidly past all the various post-Newtonian metric spaces-relativistic or not-and lands directly in cyberspace.

\section{The Web of Knowledge}

Cyberspace complies with Blake's vision of space and time. It does not exist prior to the objects it contains (the "places" that combine space and time); it expands with each site created by the "wonders Divine of Human Imagination." Cyberspace is a compact space, without voids, since it is made up solely of interconnected intellectual constructs. Its immensity is filled with thoughts. Blake gives a strikingly detailed account of this space, which he imagines structured as a "net." Here is his account, which strongly suggests the World Wide Web (Blake, Book of Urizen, plate 25, 15-22):

\section{Till a Web dark \& cold, throughout all \\ The tormented element stretch'd \\ From the sorrows of Urizens soul \\ And the Web is a Female in embrio \\ None could break the Web, no wings of fire. \\ 8. So twisted the cords, \& so knotted \\ The meshes: twisted like to the human brain \\ 9. And all calld it, The Net of Religion}

This poetic account Blake gives of the Net is not to be considered a daring premonition of the exploits of advanced information technology. However, it is meaningful to consider it metaphorically as an in-depth insight into the structure of cyberspace.

It is common knowledge that the Internet was developed partly out of the ARPA project, which aimed to provide a computer network apt to reliably channel information flows, even in the case of the destruction of some of its nodes (see, e.g., Hafner \& Lyon, 1996; Hauben \& Hauben, 1997). The Web, as a distribute d network, remains functional and is still able to provide ample information, even supposing some of its sites undergo changes, are demolished, or become inaccessible. Consequently, "none could break the Web, no wings of fire."

The intricacy of the Web ("so twisted the cords, \& so knotted the meshes") makes it similar to the human brain, a comparison that at first seems a commonplace sample from the artificial intelligence vocabulary. The Web is an interactive repository of human knowledge, which is not supplied by an individual person but by humankind at large. It may be viewed as the actualization of Karl Popper's concept of "the Third World" (Popper, 1972, p. 108).

Popper's theory of World 3 says that we can distinguis $h$ at least three different worlds of our experience. There is, first of all, the material world of computers and cables, tables and chairs, trees and plants, planets and stars. This is Popper's World 1. It is objective in the sense that it can be experienced by others, and autonomous in the sense that its existence does not depend on our own. Then 
there is the mental world of pleasures and pains, loves and hates, beliefs and dispositions. This is what Popper called World 2. It is subjective in the sense that the mental states of one mind cannot be experienced by another, and nonautonomous in the sense that their existence depends upon the existence of the mind that actually experiences them. There are, however, other things in our experience that do not fit easily into either of these worlds. There are, for example, words and statements, books and symphonies, laws, numbers, triangles, theories. These things are immaterial, unlike the objects of World 1, although they have to be embodied, at least in the magnetic surface of the servers' hard disks. But they are also objective, unlike the mental states of World 2. And when it comes to autonomy, their status seems entirely different. For while they are, according to Popper, products of the human mind, they also give rise, once they are created, to consequences that their creators neither intended nor foresaw (Notturno, 1997 [Preprint], pp. 137-138).

The elements of World 3 form the body of objective knowledge, which can eventually be used as a blueprint for reconstructing human civilization and culture. Notturno (1997 [Preprint]) argues against most philosophers who reject Popper's theory of World 3, blaming them for confusing it with Plato's theory of Ideas or with Frege's theory of the dritte Reich (third realm). The latter two were introduced, in part, to supply metaphysical scaffolding for scientific claims to certainty. But Popper, unlike Plato and Frege, did not regard scientific knowledge as certain. For Popper, the problem was not to explain how objective knowledge could be certain, but to explain how fallible knowledge could be objective. His solution was that the objectivity of scientific knowledge consists in its susceptibility to criticism. Far from supplying support for scientific claims to certainty, World 3 is introduced to supply the means for rationally criticizing them. And far from being eternal and immutable, World 3 is described as an evolutionary product of the human mind that is itself subject to further evolution (Notturno, 1997 [Preprint], p. 139).

It takes all sorts to make a world, and World 3 is by no means an exception. Cyberspace provides scientific knowledge, nonscientific knowledge, art, information (what flight to book), misleading trails, opinions, advertis ing, and so on. Not all of it fits in the framework of objective knowledge, but at least some subsets of cyberspace qualify as an emerging "Third World." Contrary to the common view, these are not elitistic, closed networks; they are open and public, since they tend to improve knowledge by a generalized debate. According to Popper, knowledge is continuously filtered out by tests, which attempt to prove its falsehood, so that only the reliable knowledge, which has survived the tests, is preserved. It is true that the nonscientific knowledge, as honorable as it may be, is not prone to falsifiability. However, the critical debate over the value of specific knowledge, be it artistic or ideologic, is still an effective tool for discerning the good from the bad. This is perfectly consistent with Blake's statement that "Establishment of Truth depends on destruction of Falshood continually" (William Blake, Jerusalem, pp. 55, 65).

The common reliable knowledge of humanity is the abstract counterpart of the unique Being that, according to William Blake, totalizes all the creation in the flesh and blood of one body (cf. Peterfreund, 1998, p. 34). Albion, the hero of Jerusalem, contemplates the multiplicity and realizes its essential unity: "They were as Adam before me: united into One Man,/They stood in innocence \& their skiey tent reached over Asia" (William Blake, Jerusalem, plate 60, II, 16-17).

Taking into account this all-encompassing vision, one gathers that the human brain Blake compares the Web to is not the brain of an individual, but the intelligence of the humankind that "walked/To \& fro in Eternity as One Man reflecting each in each \& clearly seen/And seeing: according to fitness \& order" (William Blake, Jerusalem, plate 98, 38-40). This "One Man" cannot help reminding us of Teilhard de Chardin's metaphysic of evolution, holding that it was a process converging toward a final unity that he called the omega point (de Chardin, 1955). Teilhard's scheme of evolution is the socialization of mankind. This is not the triumph of herd instinct but a cultural convergence of humanity toward a single society. Evolution has gone about as far as it can to perfect human beings physically; its next step will be social. Teilhard saw such evolution already in progress; through technology, urbanization, and modern communications, more and more links are being established between different peoples' politics, economics, and habits of thought in an apparently geometric progression. Teilhard's prospective vision has been recently revigorated by Richard Wright's contribution s to the philosophical fundamentals of biology (Wright, 2001). He asserts that the ADN/ARN genetic mechanisms are only an infrastructure of the evolutionary process, whose basic impetus is the non-zero-sum games described by Morgenstern and von Neumann (1980), that is, the complex strategies that combine competition with cooperation. Contrary to the biologists' conviction that the evolution of species is the result of an adaptive process to environmental shocks, Wright sees intraspecie s emulation as the decisive factor of progress. The ambient that most stimulates the evolution is the social one. Taking for granted that humankind keeps adopting non-zero-sum games to maintain evolution, this cannot be managed in the absence of communicational infrastructures. That is why evolution was sped up by the increase of population density. According to Wright, cyberspace provides the medium that connects the individual consciences in a gigantic, multicultural mega-brain, the equivalent of Teilhard's "omega point" (Wright, 2001, p. 327). 
Blake is by no means enthusiastic about the virtues of the Web. He sees it "dark and cold, stretch'd from the sorrows of Urizens soul." We follow here Peterfreund's interpretation of Urizen as the personification of Reason, which governed the scientific revolution of the 16th century (cf. Peterfreund, 1998, p. 35). Reason's soul is sorrowful because devoid of the impetus of poetical inspiration; therefore, the Web (of knowledge) it brings forth is "dark and cold." The little corpuscles, which are thought to form the basis of Reality, comprise, according to Newton himself, the feminized frame of Nature (cf. p. 226, note 34). Consequently, the Web "is a Female in embrio," it suggests a degraded state of knowledge. We should not be misled by Blake's conclusive statement, "And all calld it," The Net of Religion, because Religion is seen here as a reified institution, which has long lost the prophetic inspiration of its origins, thus being reduced to a sort of pragmatic reasonability (cf. p. 88).

Bacon, Newton, and Locke, as cavaliers of Reason, are to blame for the new conceptual frames they imposed, which provided only a narrow, crooked understanding of the life and of the world. They have worked in guilty connivance at the construction of the (dark and cold) web of knowledge, in which we may contemplate "Newton's Pantokrator weaving the Woof of Locke" (William Blake, Milton, plate 4, II, 11). Blake thinks it is the artist's duty to redeem the web and to transform it into an eternal delight. To this end, he put the multimedia to work.

\section{CYBER SPACE-TIME AND REAL LIFE}

Cyberspace (or, better said, cyber space-time) is the area wherein a distinctive population works, socializes, builds up friendships and love bonds, develops new skills and specific rules of behavior, ponders its identity, and experiments with new forms of organization. It is, to be sure, a very diversified society, but, however heterogeneous, it shares meanings, values, and beliefs that, structured as cyberculture, lend it a unitary profile. It is obvious that every person pertaining to cyberspace is also part of the real-life world. This commonplace truth prevents many an observer from seeing the distinction between the two. However, the argument that people from cyberspace belong necessarily to real life too and, consequently, there is not any frontier between the two spaces is surely irrelevant. The development of industry and banking contributed to the advent of the cities and brought about the urban cultural space, clearly distinct from the rural one. Obviously, the town people involved in industry, commerce, art, or letters continued to consume agricultural products and to make frequent visits to the countryside. This did not, however, smooth down the differences between the rural and the urban modes of life, and did not abolish the invisible frontier between the two spaces.
Similarly, cyber-people continue to eat, to drive cars, and to live in houses, but the main (and best) part of their lifework, play, reflection, interaction-goes on in cyberspace. They are not primary producers and would be quite at a loss when confronted with basic issues, like surviving in wilderness or after a major natural disaster. However, one can easily surmise that the sudden disparition of food on the market would similarly embarrass many a real-life citizen.

As far as information exchange is concerned, the cyber space-time continuum takes over from real life only the concept of discourse, that is, the organization of signs in a significant pattern. Discourses in cyberspace have multiple sources and multiple targets. The time of the few centralized emitters is gone. Every cyber-person is wrung between the drive for expression and the thirst for information. You have to silence the other and lure him to pay attention to you, that is, to give you his time, the most precious resource in cyberspace. On the other hand, you are also prepared to listen; sometimes you are even craving an answer. Consequently, there is a permanent exchange of information, but it is not directly reciprocal. I may not require your information content while delighting in giving you mine. I may speak to you, then listen to another person. The only thing that mediates all informational exchanges is time. One buys my information and pays with his time, I buy my information and pay with my time. Time plays in cyberspace the part that money plays in real life; "time is money" indeed-it is the abstract equivalent of any merchandise, be it information, knowledge, or whatever, the sign of all the signs. The discourses do not fight each other; more often than not they just pass along each other, like ships in the dark. They slide along the fabric of cyberspace, moving with the time.

\section{NOTES}

1. Contrary to cyberspace, these are mostly metric spaces, as will be shown in the sequel.

2. El sueño del razon produce monstruos, the front page of Goya's Caprichos, expressed the common doxa at the end of the XVIIIth century.

\section{REFERENCES}

Coyne, R. 1995. Designing information technology in the postmodern age: From method to metaphor. Cambridge, MA: MIT Press.

de Chardin, T. 1955. Le phénomène humain. Paris: Gallimard.

Erdman, D. V., ed. 1982. The Complete Poetry and Prose of William Blake. Los Angeles: University of California Press.

Gibson, W. 1984. Neuromancer. New York: Ace Books.

Hafner, K., and Lyon, M. 1996. Where wizards stay up late: The origins of the Internet. New York: Simon \& Schuster.

Hauben, M., and Hauben, R. 1997. Netizens: On the history and impact of Usenet and the Internet. New York: IEEE Computer Society Press. 
Introna, L. D., and Nissenbaum, H. 1999. The politics of search engines. The Information Society 16(3):169-185.

Kaplan, N. 2000. Blake's problem and ours: Some reflections on the image and the work. In The emerging cyberculture: Literacy, paradigm and paradox, eds. Stephanie B. Gibson and Ollie O. Oviedo, 26-43. Creskill, NJ: Hampton Press.

Kolko, B. E., Nakamura, L., and Rodman, G. B., eds. 2000. Race in cyberspace. New York: Routledge.

Malraux, A. 1965. Le musée imaginaire. Paris: Gallimard.

Morgenstern, O., and von Neumann, J. 1980. Theory of games and economic behavior. Princeton, NJ: Princeton University Press. (First edition 1945.)

Notturno, M. A. 1997. Science and the open society: In defense of reason and the freedom of thought [Preprint]. Budapest: Central European University.

Peterfreund, S. 1998. William Blake in a Newtonian world: Essays on literature as art and science. Norman: University of Oklahoma Press.

Popper, K. R. 1972. Epistemology without a knowing subject. In Objective knowledge, ed. Karl R. Popper, pp. 84-136. Oxford: Clarendon Press.
Ralph, E. 1985. Geographical experiences and being-in-the-world: The phenomonological origins of geography. In Dwelling, place and environment: Towards a phenomenology of person and world, eds. David Seamon and Robert Mugeraur, pp. 15-36. Nijhoff: Dordrecht.

Resource Centre for Cyberculture Studies. 2001. Accessed 03.10.2000. Archived at www.otal.umd.edu/\%7Erccs/

Rieusset-Lemarié, I. 2000/2001. De al teneur à l'hypertexture numérique de l'æuvre: l'ethétique de la dissémination à l'ère de la reproduction multimédia. Webzine: Solaris, December 2000/January 2001.

Sardar, Z., and Ravetz, J. R., eds. 1996. Cyberfutures: Culture and politics on the informational superhighway. New York: New York University Press.

Sewall, L. 1999. Sight and sensibility: The ecopsychology of perception. New York: Jeremy P. Tarcher/Putnam.

Wertheim, M. 1999. The pearly gates of cyberspace: A history of space from Dante to the Internet. New York: W. W. Norton.

Wright, R. 2001. Non-zero: The logic of human destiny. New York: Vintage Books. 